AperTO - Archivio Istituzionale Open Access dell'Università di Torino

\title{
Reputation by Design: Using VDML and Service ML for Reputation Systems Modeling
}

\section{This is the author's manuscript}

Original Citation:

\section{Availability:}

This version is available http://hdl.handle.net/2318/158344

since

Publisher:

IEEE Computer Society

Published version:

DOI:10.1109/ICEBE.2014.41

Terms of use:

Open Access

Anyone can freely access the full text of works made available as "Open Access". Works made available under a Creative Commons license can be used according to the terms and conditions of said license. Use of all other works requires consent of the right holder (author or publisher) if not exempted from copyright protection by the applicable law. 


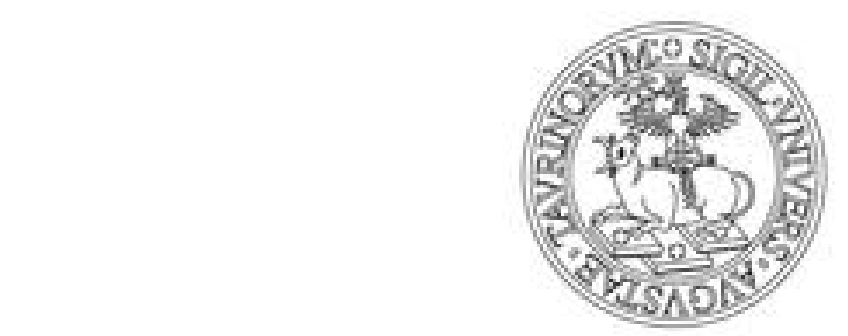

\section{UNIVERSITÀ DEGLI STUDI DI TORINO}

This is an author version of the contribution published on:

S. Capecchi, P.Pisano

Reputation by Design: Using VDML and Service ML for Reputation Systems Modeling

Editor: IEEE Computer Society

2014

ISBN: 9781479965625

in

PROCEEDINGS of The Eleventh IEEE International Conference on E-Business Engineering ICEBE 2014

$191-198$

ICEBE 2014

Guangzhou, Cina

$5-7 / 11 / 2014$

The definitive version is available at:

http://ieeexplore.ieee.org/lpdocs/epic03/wrapper.htm?arnumber=6982079 


\section{Reputation by design: using VDML and ServiceML for reputation systems modeling}

\author{
Sara Capecchi \\ Dipartimento di Informatica, \\ Università di Torino \\ capecchi@di.unito.it
}

\author{
Paola Pisano \\ Dipartimento di Informatica, \\ Università di Torino \\ pisano@di.unito.it
}

\begin{abstract}
Despite reputation deeply influences system providers and users interactions (e.g. in e-commerce), today implementations of reputation systems are far from being satisfactory. Reputation systems implemented so far for ecommerce are very simple and lack in showing relevant features of the service: on the one hand the representation of reputation does not distinguish different attributes concerning the entity holding the reputation; on the other hand the information used to built reputation is completely subjective, that is entirely rely on users' feedbacks, even concerning attributes that could be objectively measured. The principal cause of the problems above is that software engineering methodologies captures high level functional requirements and detail them down to system implementation but not on the reputation system side. In the present paper we start to tackle the highlighted problems by proposing an extension of Value Delivery Modeling Language and Service Modeling Language toward the representation of reputation systems concepts. The aim is to provide a model to represent reputation requirements of the system-to-be from the very beginning in the software development.
\end{abstract}

\section{INTRODUCTION}

Reputation can be defined as an expectation about an entity's behaviour based on informations about or observations of its past behaviour and it is used to make a value judgment about another entity (object or person). Despite reputation deeply influences interactions between users, services and service providers today implementations of reputation systems (to help users in choosing among services and to help services in improving their proposal) are far from being satisfactory. On the one hand, inspite of the latest governments' efforts to use new technologies in order to improve citizen participation and information exchange between citizens and government, reputation system evaluating public services (schools, hospitals, administration) are almost absent. On the other hand reputation systems implemented so far for e-commerce are very simple and lack in showing relevant features of the service: 1) the final representation often fails to distinguish different attributes/characteristics concerning the entity holding the reputation. The resulting value is an overall one that does not reflect the related contexts in which it is earned; 2) the information used to built reputation is completely subjective, that is entirely rely on users' feedbacks, even concerning attributes that could be objectively measured (e.g. delivery latency or security of payment in the case of e-commerce).

As a matter of fact there are lots of sources holding objective informations that could and should be used to compose a service reputation together with users' feedbacks: quality control and guarantee organizations/companies exist for a wide range of topics, products, specialities and services; their goal is to control the quality of developing systems to ensure products or services are designed and produced to meet customer needs; open data provided by administrations in the latest trend of Open Government can contain relevant informations concerning public services. Nowadays all these sources are rarely evaluated from users because they are neither easily reachable nor represented in a clear mode. Instead, they should be put in a readable format that can be understood by users/customers of a service and integrate their feedbacks in a reputation system. Thus, the issue is not of who to trust standardization/public organizations or users ratings. The two sources should be related to different aspects of a business and integrated in order to built a more articulated reputation. Summarizing in current reputation systems there is a wide room for improvement concerning what is being shared and how it is being shared: despite its subjective nature, reputation can be built in a way that provides a sufficient degree of objectivity and automation by analysing and collecting data related to some part of the service. While such structured information may not capture the completeness of a written rating, it should be enough for the vast majority of practical considerations.

One of the main causes of the deficiencies above described is that software engineering methodologies do not provide the right level of support for reputation system, starting from the very early stages, that is, by the use of a dedicated conceptual model and the related modeling language. So far reputation models have been added after-the-fac in an ad-hoc perspective, limiting re-usability and suffering scalability problems. The entities that play a role in a reputation system (i.e. users, services, products, transactions), should be expressed and modeled at a business level, so to allow mutual understanding between requirements engineers and stakeholders avoiding the socio-technical mismatch in communication that can delay and harm the system development: the right conceptual model to reason about reputation systems is one where all entities related to business models are represented. According to Teece [1] business model reflects managements hypothesis about what customers want, how they want it, what they will pay and how an enterprise can organize to best meet customer needs. Business model simplifies how organisation structures all the activities and resources to develop the right value proposition to the right clients and finally get money from all these processes. 
In the present paper we start to tackle the above issues by proposing an extension of Value Delivery Modeling Language (VDML) and Service Modeling Language (Service ML) [2] towards the representation of concepts and requirements for reputation systems. VDML abstracts the organization structure of an enterprise, the creation and exchange of value, the capabilities that produce that value, the management of resources people and roles, interactions with business partners; ServiceML Touchpoint model allow to describe the customer experience while using a service. These languages provides the right abstractions to represent the concepts related to reputation systems in the design phase when role and entities must be clearly detected: reputation sources and target roles (service user, service provider, certification service third party), parts of the service that can be objectively and subjectively evaluated etc. The aim is to provide a model to allow mutual understanding between reputation system committee and designers. For the sake of clarity in the rest of the paper we use a simple leading example representing an e-store.

Example: personalised T-shirt online store. We consider an online store which provides customized T-shirts. Customers enter website, create their own T-shirt by uploading images and, if they are satisfied by the displayed prototype they buy the product. After receiving the item, customers can benefit from a customer care service which handle returns, claims and product assistance.

The rest of the paper is organised as follows: Section 2 resumes problems related to reputation systems and the conceptual abstractions needed; Section 3 describes the parts of VDML and ServiceML that are used in our proposal; Section 4 presents our extension of the two languages towards reputation modeling; Section 5 discusses related works; Section 6 concludes the paper and lists our current and future works.

\section{MODELING REQUIREMENTS FOR REPUTATION SYSTEMS}

Terminology. First, following [3] we introduce the terminology used to refer to basic objects involved in a reputation system. Reputation is composed of reputation statements with the following structure: a source makes a claim about a target. A source is any entity that can make a reputation claim (users, third party certifications etc.). A claim is the value that the source assign to the target. Claims have a type and a value. In the present paper we abstract from different types of claims (quantitative vs qualitative, raw vs normalised), we just distinguish between claims that come from a subjective opinion and those coming from an objective measurement: for instance a claim about delivery service of an e-store could come from subjective comments of customers or from objective data (percentage of delivery delays, percentage of damaged packagings). A target is any reputable entity that can be the object of a reputation claim. To summarise let us consider the following reputation statement: user $\mathrm{x}$ rates 4 stars over 5 product $y$; user $\mathrm{x}$ is the source, 5 star is the claim type, 4 star is the claim value, product $y$ is the target.

Reputation systems problems. As outlined in [4], [5], [6] existing reputation systems show many deficiencies:

- lack of connection between reputation statements and its context, e.g judgement about product, delivery, price, interaction with seller is melted in a 5 star claim type plus a detailed written feedback: the resulting value is an overall one that does not reflect the related contexts in which it is earned. In order to get details about the general score users must read in detail written feedbacks: this can be a cumbersome task giving just a partial view of the feedbacks totality

- incomplete or non-comprehensive provided information which causes incorrect perception of the service reputation by the user (for instance a good online store could be blamed for bad scores resulting from inefficient delivery company, informations provided by certifications could be difficult to understand for users without technical knowledge)

- no distinction between expressions of fact and opinion, that is between objective and subjective claims

- lack of a proper identification mechanism that should allow only effective users of a service to evaluate it thus avoiding fake feedbacks

Reputation systems abstraction requirements. In order to overcome the problems above an adequate modeling language should be able to represent:

- $\quad$ source and target roles

- $\quad$ target entities that can be subjectively and objectively measured

- the complete multiplicity of targets that compose an overall service/value

- the link between targets of claims and roles in the business service responsible for them: each part of a service that is evaluated should be directly and easily connected with roles and actors responsible for it in the business organisation

The above concepts should be detected in a model which describe the activities, competences, resources and skill are strictly linked and connected to create the value delivered by the organization to customers, that is, a business model.

Which model? To support the creation of highly complex businesses that deal with volatile technologies new procedures for creating and testing business models have emerged. One of these developments is the CUBE model proposed in [7], a conceptual instrument that helps the definition of 1) customers 2) value proposition 3) value formula 4) network partners 5) capabilities 6) activities. Customers represent that segment of buyer interested in the value proposition of the organization; value proposition gives an overall view of the target customer, the product and service offering. It defines what choices and trade offs the firm will make; value formula is a realistic view of the sources of revenue and cost; network partners represent all the voluntarily initiated cooperative agreement between two or more companies in order to create value for the customer; capabilities are the competencies necessary that should be created, nurtured and developed in house and contribute to the power of a business model; activities are all the operations to put in action value proposition. In a simplified scheme the CUBE model contains the objects, concepts and their relationships, expressing the logic underlying the business. If 

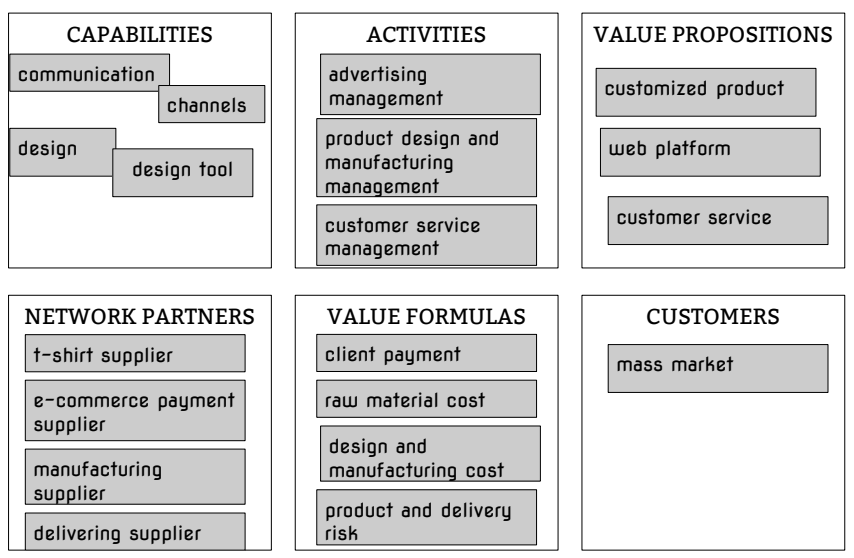

Fig. 1. T-shirt online store business cube

the block 1 is related to the customers engagement, block 2 describes the value proposition, blocks from 4 to 6 regard to the functions of logistics and manufacturing and articulate the relationships between key partners (employees, suppliers) and the company. According to Hulme [8] the use model as CUBE MODEL is essential not only for involves entrepreneurs (undertaking an exercise of constant reflection, developing the business model using graphical tool where all the elements are related to each other) but also to develop a common language that allows entrepreneurs, customers, employees, executives and even competitors to understand how the business articulates its different components. Therefore its use facilitates communication with the different stakeholders becoming the starting point of discussion about new opportunities, how to align the activities to the firm's mission and vision of the firms, how to understand what actors is involved in which processes and for which value delivering facilitates the identification of risks and failures.

Figure 1 describes the cube model associated to our example. The value proposition delivered by the store is centred on product customization reached by the web platform. Customers have not specific characteristics apart form the ability of using internet service. The key capabilities are centred on both communication and design useful to amplify the user experience, consequently advertising and customer services are key activities as well as the product development. Our organization needs to structure a network based on supplier partnership which represents the cost of the value formula.

Value Delivery Modeling Language supports the six views of the cube with dedicated diagrams. VDML provides abstraction for modeling of value creation and exchange, capabilities and capability sharing, organizational relationships and performance measurements. VDML is under development as an OMG (Object Management Group [9]) standard. In the following section we provide a brief overview of the VDML principal concepts and their relationships concentrating on those needed for our purpose. The overview also include Service Journey Maps taken from Service Modeling Language that is also used toward reputation modeling in Section IV.

\section{VDML AND SERVICEML}

In the following we briefly resume the concepts that can be represented by VDML notation and diagrams.

Collaborations and roles. A collaboration is defined as a group of participants, working together for a shared purpose. An enterprise involves networked collaborations i.e. with customers and suppliers. Roles within a collaboration define how each participant contribute to the collaboration. A participant can be an actor (person or automaton), a supporting collaboration or another role. For example, a manager (role) of an organization (collaboration) can be assigned as a member (role) of a task force (collaboration).

Activities. Define what participants do in their roles. Activities receive business items and add value to produce business items as deliverables.

Capabilities. Each capability identifies the organization units in an enterprise that can provide that capability. Each activity requires a capability and identifies the role of an assigned participant that has the capability to perform the activity. The activity defines how that capability contributes to the particular collaboration.

Values and value proposition. Activities add value to produce deliverables. From contributing activities, value adds of each type are aggregated in a value proposition that represents the values of the product or service. A value proposition is a package of values and deliverable(s) that are offered to a recipient, typically a customer, but a value proposition can also be offered to other stakeholders such as business owners or internal customers.

VDML provides several diagrams to represent the abstractions above and their relations. In this paper we use Value exchange proposition diagram which depicts roles and exchanged products and services expressed as value propositions. The value proposition exchange diagram related to our example is illustrated in Figure 2. Value proposition is composed by eight elements divided into two groups: 1) first group: it's the closest to the customer perception and composed by printed T-shirt, website and customer care. These elements depend by in-house company expertise; 2) second group: it's the closest to the partners and it's composed by payment facilities, delivery service, T-shirts, prints and certification. These elements depend by out-house partnership expertise.

For what concerns representation of activities we rely on SeviceML Service Journey Maps. ServiceML has been created to support service innovation capabilities following the AT-ONE method [10] which is based on 5 lenses (Actors, Touchpoints, Offerings, Needs, Experiences) and their interplay. ServiceML comprises 3 languages: Business-SoaML a SoaML extension toward business aspects while covering the architectural side of a service oriented architecture, LightUSDL which provides interface descriptions for business based on the USDL (Unified Service Description Language) and Service Journey Maps. In the present paper we just focus on Service Journey Maps which describe the typical flow of activities, encapsulated as a touchpoint, which a participant, service provider and other stakeholders perform in a service execution. Figure 3 illustrates how a service consumer creates and buy a customised T-shirt in the online store of our leading 


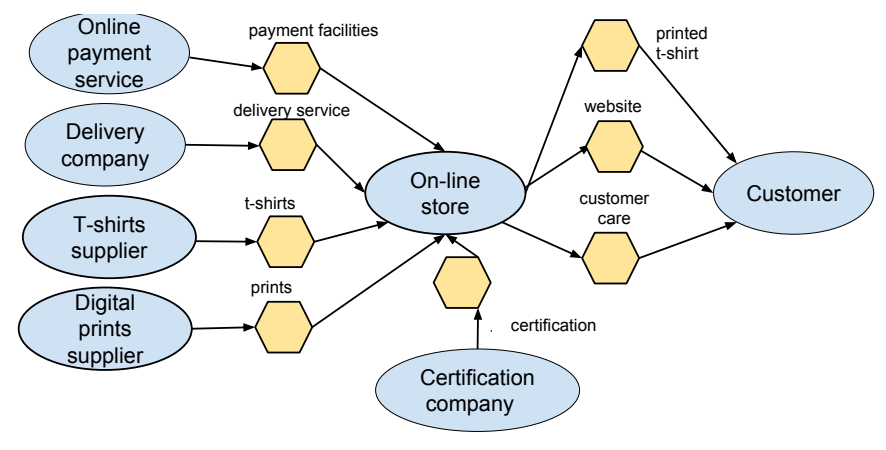

Legend

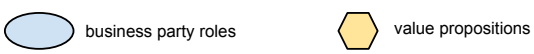

Fig. 2. Value proposition exchange diagram of T-shirt online store

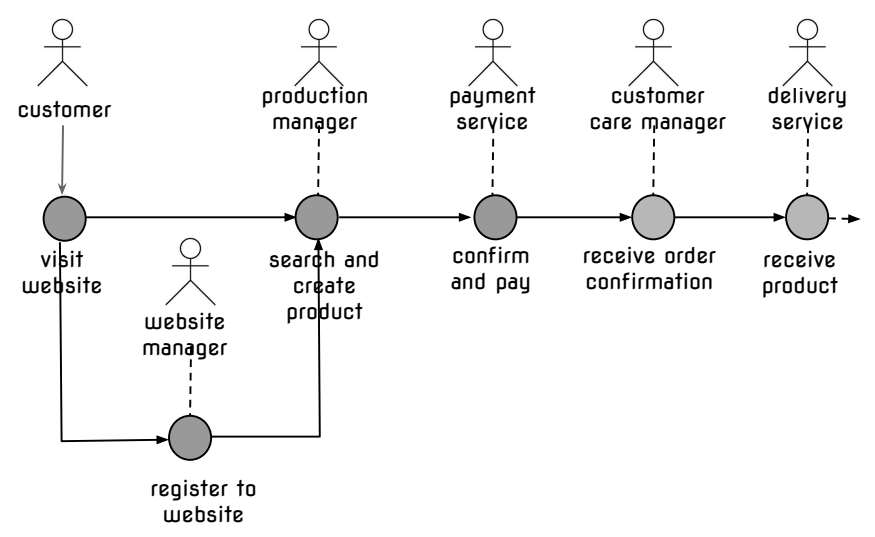

Fig. 3. T-shirt online store service journey map

example. An actor can either initiate a touchpoint (represented by open arrows like the one from customer to visit website) or be involved, through some inputs or outputs, in a touchpoint execution (represented by dotted lines). Closed arrows link one touchpoint to the next following execution sequence. A service consumer of the online store creates and buys a customised T-shirt using T-shirt store website by first having to register as a member, if required, (this touchpoint involves website manager role), and then creating a T-shirt using a dedicated software that displays T-shirt prototypes with images printed on it (involves production manager), paying for the order (involves the payment service to verify payment), receiving order confirmation (involves customer care manager) and finally receiving the product (involves delivery service). A service journey map helps to understand how services are being experienced by customers. Therefore, ServiceML Touchpoints offer a great model to involve stakeholders in designing service feedback.

VDML and ServiceML alignment. The mapping between VDML and serviceML service journey map taken from [2] is shown in Figure 4 (which includes also elements of our extension that will be presented in Section IV). In the following we only summarise correlations which are in the scope of the present paper.

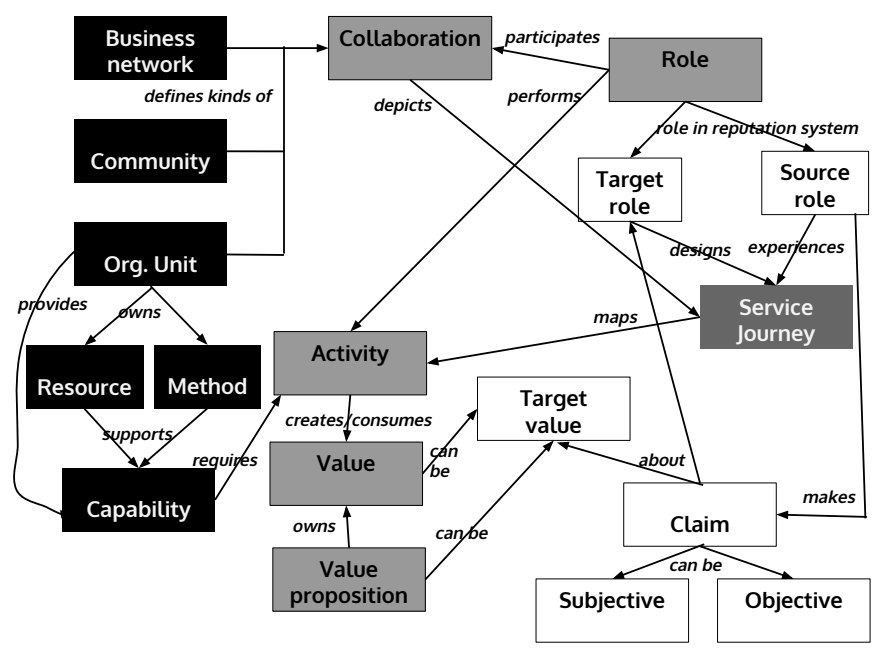

Fig. 4. VDML and ServiceML alignment + reputation concepts extension Legend: black boxes $=$ VDML elements, grey boxes with black font $=$ VDML and ServiceML common elements, grey boxes with white font: ServiceML elements, white boxes: elements added by our extension.

Collaborations. A collaboration in VDML is a collection of business networks, organizational units etc. interacting for business purposes. In ServiceML, the notion of a collaboration is required to perform service journeys.

Roles. A VDML role performs activities defined in a service collaboration. Roles can be assigned to VDML participants in order to specify which actor or group of actors should fulfil the role and perform the set of associated activities. Similarly, ServiceML roles design/express service journeys and provide/receive value propositions.

Activities. A VDML activity is a work executed within the context of a collaboration. A participant creates or consumes value by performing an activity. From the ServiceML side, service journeys are translated into a set of activities to be carried out by participants.

In Figure 4 on ServiceML side we just represent Service Journey Maps element since it is the only one we use, we refer to [2] for a complete description of ServiceML features.

\section{EXTENDING VDML AND SERVICEML TOWARD REPUTATION SYSTEM DESIGN}

In order to represent the abstractions needed to model reputation systems requirements identified in Section II we extend VDML by providing roles and value proposition specialisations and new relations between them. We explain our extension throughout our T-shirt online store example (Figure 5).

Roles. We specialise roles according to their part in the reputation system: source and target. A source role is any participant that can make a claim about a target and is identified with a thick oval. In our example source roles are customer who can express claims about any aspect of the service, online payment service that can provide data and evidences about the payment procedure, the delivery company that can do the same about delivery and the certification company that provides a certification about the quality of customer care service. A 


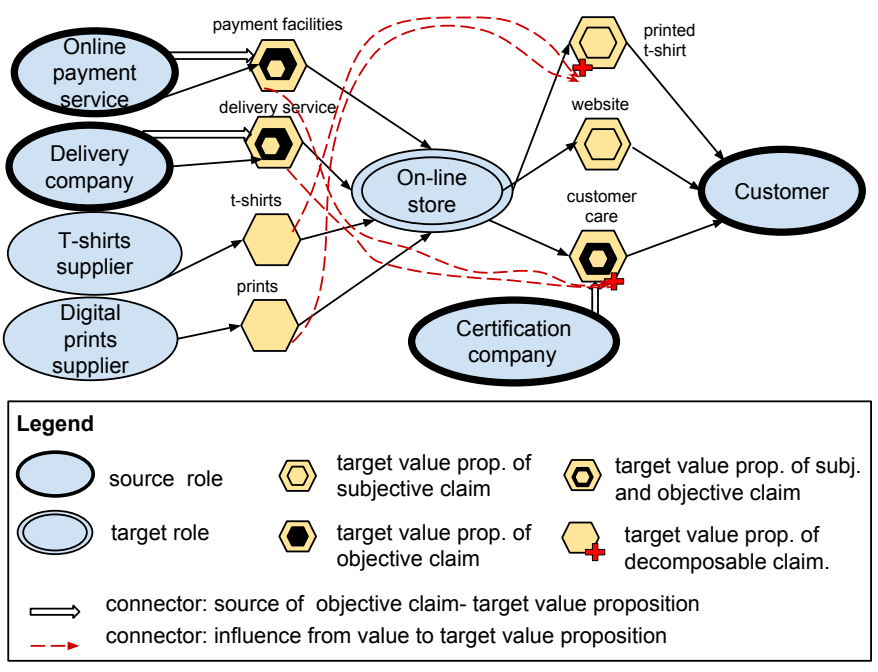

Fig. 5. Value proposition exchange diagram of T-shirt online store extended with reputation modeling.

target role is any participant that is the object of a reputation system and it is represented with a double oval. In our example the target of the reputation system is the online store.

Value proposition. Value propositions are the ideal target of reputation claims: source roles provide their judgements, data and measurements about products and services that compose value propositions. As pointed out in previous sections, targets of reputation statements can be evaluated with objective data and measurements or with subjective comments/ratings. Then, value propositions can be target of objective, subjective claims or both. We denote them with three different kinds of hexagons depicted in Figure 5:

- $\quad$ payment facilities, delivery service and customer care can be evaluated objectively (from providers collecting data) and subjectively (from users)

- the website and printed T-shirt can be evaluated subjectively by users.

White arrows represent a connection between a source role and its objectively measured target: in our example they connect online payment service with payment facilities, delivery company with delivery service (since they both provide data about their value proposition) and certification company with customer care. For simplicity we do not represent the relation between source and target of a subjective claim. The reason is that the source of subjective claims is usually a customer/user whose experience in using the service is analysed in the following throughout the use of ServiceML service journey maps. Target value propositions decorated with a red cross can be further decomposed in other targets with associated claims. In our example a claim about the printed T-shirt can be further decomposed in two parts: one about the T-shirt and one about the print of the image uploaded by the customer; these two parts correspond to value propositions provided by business partners T-shirt supplier and digital print supplier to the online store (T-shirts and print). The above dependency between value propositions is represented with a red dashed arrow from T-shirts and prints to printed T-shirt.

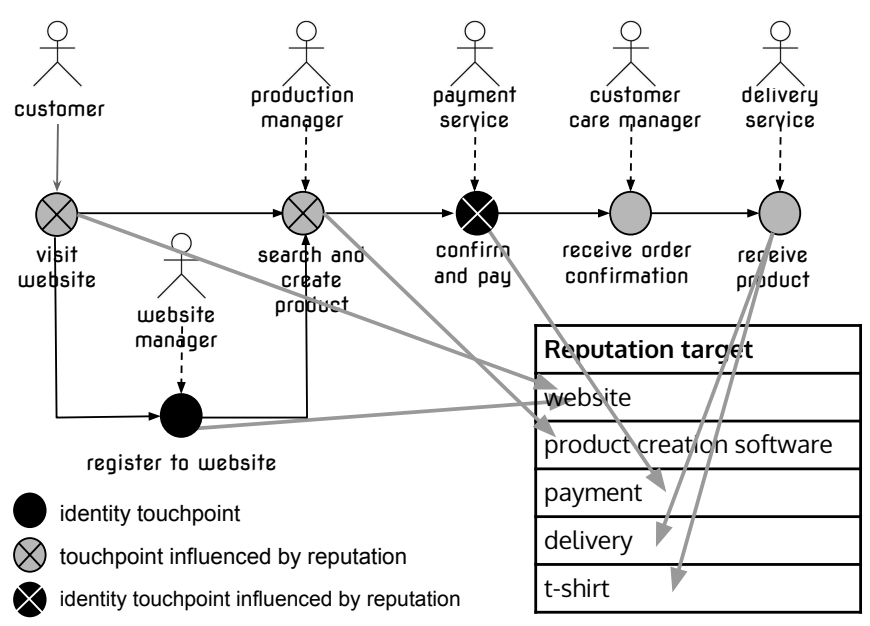

Fig. 6. T-shirt online store service journey map extension

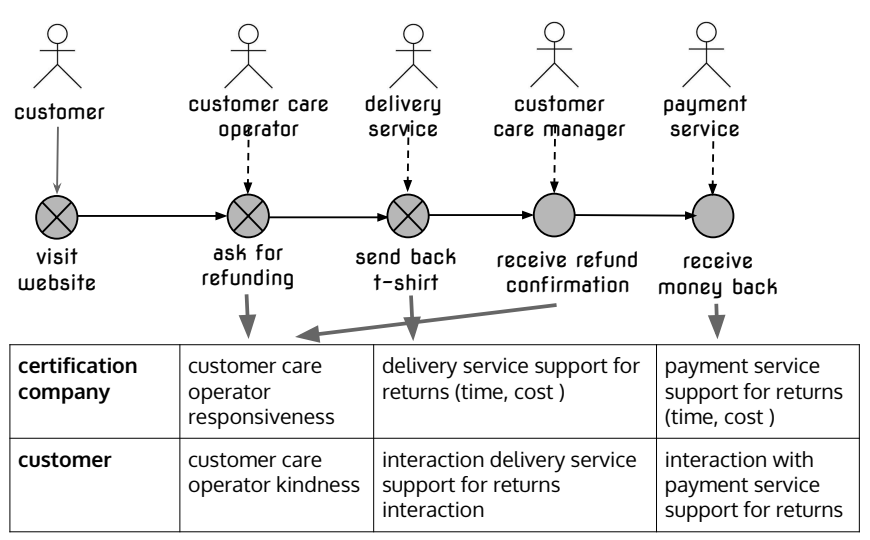

Fig. 7. T-shirt online store - customer care service journey map

Touchpoints. We also use ServiceML service journey maps which represent the phases of customer experience mapping them to precise reputation targets. We add two kinds of touchpoints: verification touchpoints are used to represent points of interaction where reputation claim validity can be checked, for instance by assigning a precise identity to the user and/or by detecting a proof that she really used the service; touchpoints influenced by reputation are those touchpoints where the user behaviour can be influenced by reputation of the service. For instance in Figure 6 we identify the registration to the website as the touchpoint where a user can be uniquely identified and the payment as the confirmation that the user has effectively used the service: this will help in designing solutions to avoid fake feedbacks. The behaviour of a customer in visit website, search and create product and confirm and pay touchpoints is influenced by the reputation of the service: a customer is more encouraged to visit online store and buy from it if its reputation is good. The different touchpoints a customer encounters during its journey can also be related to corresponding targets of reputation claims. In order to evaluate the online store the customer could express claims about different aspects: website, software for T-shirt prototype creation, payment, delivery, product.

We now analyse customer care by using the service jour- 


\begin{tabular}{|c|c|c|c|c|}
\hline $\begin{array}{c}\text { Reputation } \\
\text { Source }\end{array}$ & $\begin{array}{c}\text { Reputation } \\
\text { Target }\end{array}$ & $\begin{array}{c}\text { Subj/ } \\
\text { Obj }\end{array}$ & $\begin{array}{c}\text { Associated value } \\
\text { proposition }\end{array}$ & Responsible role \\
\hline Customer & website & $\mathrm{S}$ & website & website manager \\
\hline Customer & product creation & $\mathrm{S}$ & $\begin{array}{c}\text { product creation } \\
\text { software }\end{array}$ & software developer \\
\hline Customer & payment & $\mathrm{S}$ & payment & payment service \\
\hline Customer & delivery & $\mathrm{S}$ & delivery & delivery service \\
\hline Customer & printed t-shirt & $\mathrm{S}$ & $\begin{array}{c}\text { printed } \\
\text { t-shirt }\end{array}$ & $\begin{array}{c}\text { t-shirts supplier } \\
\text { digital prints } \\
\text { supplier }\end{array}$ \\
\hline Customer & $\begin{array}{c}\text { customer care } \\
\text { operator kindness }\end{array}$ & $\mathrm{S}$ & customer care & $\begin{array}{c}\text { customer care } \\
\text { operator }\end{array}$ \\
\hline Customer & $\begin{array}{c}\text { delivery service } \\
\text { support for returns }\end{array}$ & $\mathrm{S}$ & delivery service & delivery service \\
\hline Customer & $\begin{array}{c}\text { payment service } \\
\text { support for returns }\end{array}$ & $\mathrm{S}$ & payment service & payment service \\
\hline
\end{tabular}

Fig. 8. Summary of source-subjective targets pairs associated with the corresponding value proposition and the role responsible for creating it.

ney map in Figure 7 describing a customer asking for a refund. Once again we identify some touchpoints in which the customer behaviour may be influenced by the service reputation: the decision to ask for a refund could be influenced by the reputation of the customer care service. Also in this case different touchpoints correspond to different targets of reputation claims. As summarised in the table shown in Figure 7 customer care can be evaluated from two different sources: the certification company, which provides objective claims (as indicated in Figure 5) and the customer who can subjectively evaluate it. Recall that in Figure 5 the customer care target value proposition is modeled as decomposable (hexagon with a red cross) and influenced by payment and delivery service value propositions (dashed red arrows); the above service journey map and the associated table provide details about this decomposition and the influence between value propositions; indeed customer care value proposition target is decomposed in three blocks depicted in the associated table: for instance, the first is related to the ask for refunding touchpoint; in this case the certification company can provide objective data about the time between user's request and service response while the customer can rate operator's kindness. The influences of payment and delivery service on customer care are cleared here since the success of refund depend also on support for refund by payment and delivery service.

The analysis performed so far can be summarised in Figures 8,9 where all the reputation source-target pairs are associated with 1) an attribute indicating if they are related to objective or subjective claim, 2) the corresponding value proposition and 3) the role responsible for creating it.

This tables can be used by developers and online store consultants and managers to reason about the shape of the reputation system associated to the store: what are the objective informations that can/should be displayed to customers? What are the fields of a feedback form that customers should fill when rating the store?

The connection between reputation target, value proposition and the roles responsible for producing it will provide information needed by managers to improve activity and operations, to understand their impact on the rest of the business

\begin{tabular}{|c|c|c|c|c|}
\hline $\begin{array}{c}\text { Reputation } \\
\text { Source }\end{array}$ & $\begin{array}{c}\text { Reputation } \\
\text { Target }\end{array}$ & $\begin{array}{c}\text { Subj/ } \\
\text { Obj }\end{array}$ & $\begin{array}{c}\text { Associated value } \\
\text { proposition }\end{array}$ & Responsible role \\
\hline $\begin{array}{c}\text { Delivery } \\
\text { company }\end{array}$ & delivery time & 0 & delivery service & delivery company \\
\hline $\begin{array}{c}\text { Payment } \\
\text { company }\end{array}$ & payment security & 0 & payment service & payment company \\
\hline $\begin{array}{c}\text { Certification } \\
\text { company }\end{array}$ & $\begin{array}{c}\text { customer care } \\
\text { operator } \\
\text { responsiveness }\end{array}$ & 0 & website & website manager \\
\hline $\begin{array}{c}\text { Certification } \\
\text { company }\end{array}$ & $\begin{array}{c}\text { delivery service cost } \\
\text { for returns }\end{array}$ & 0 & $\begin{array}{c}\text { product creation } \\
\text { software }\end{array}$ & software developer \\
\hline $\begin{array}{c}\text { Certification } \\
\text { company }\end{array}$ & $\begin{array}{c}\text { delivery service } \\
\text { time for returns }\end{array}$ & 0 & payment & payment service \\
\hline $\begin{array}{c}\text { Certification } \\
\text { company }\end{array}$ & $\begin{array}{c}\text { payment service } \\
\text { cost for returns }\end{array}$ & 0 & delivery & delivery service \\
\hline $\begin{array}{c}\text { Certification } \\
\text { company }\end{array}$ & $\begin{array}{c}\text { payment service } \\
\text { time for returns }\end{array}$ & 0 & $\begin{array}{c}\text { printed } \\
\text { t-shirt }\end{array}$ & t-shirts digital \\
prints supplier \\
\hline
\end{tabular}

Fig. 9. Summary of source-objective targets pairs associated with the corresponding value proposition and the role responsible for creating it.

and how reorganise collaborations between internal units and departments and with external business partners. This will be possible by exploiting the features of VDML diagrams which relates all the part of the business cube.

\section{RELATED WORKS}

There are few works that consider reputation requirements at the early stages of system design. Reputation Object Model [4] is a conceptual model identifying many concepts related to reputation systems. [11] propose and extension of UML for specifying trust and reputation requirements. Some of these concepts can be easily mapped to ours, while others related to reputation claims measurements, computing functions and collecting algorithms are not present in our proposal. The reason is that, so far, we have addressed the problem of modeling reputation objects and not reputation measurements and algorithms. A future step in this direction is discussed in Section VI. The distinguishing feature of our proposal is that we model reputation-related concepts on a modeling language that has been expressively designed for overcoming the sociotechnical mismatch that is usually present between developers and business committees.

We refer to [3] and [6] for a description of development methodology that should be followed when designing and developing reputation systems.

In [2] service journey's touchpoints are decorated with a level of satisfaction that comes from users' feedbacks. We took inspiration from their emotional touchpoints to map different stages of users' journey to fields of users' feedbacks surveys.

\section{CONCLUSION AND FUTURE WORK.}

In this paper we made a first step in providing a disciplined methodology to support IT designers in the capture of highlevel reputation management requirements and their implementation. Starting from VDML and ServiceML we propose a conceptual model and a methodology to detect reputation sources, target and claims. The result of the proposed methodology for reputation system requirements analysis is a complete set of subjective and objective targets: 
- $\quad$ subjective claims can be used to structure and display data provided by standardisations/certifications

- objective claims can be used to design surveys for customers feedback collection.

The new proposed methodology should also encourage the design of users surveys in a way that the criteria that compose the reputation of the services are clearly modeled and rated separately so that an evaluation of an entity is not generalized anymore. Each value in can be related to a certain context therefore giving the opportunity of easier storage and elaboration of feedback to improve services. More specifically the benefits for developers could be listed as:

- consistent terminology

- appropriate levels of abstraction facilitating the development of the model in several domains and ensuring the simplicity and reusability of the embedded information

- $\quad$ support for identifying the appropriate stakeholders, users and relevant sources of informations

Moreover, linking customer feedbacks as part of an appropriate reputation systems to specific business model elements can easily improve the organization output in line with the customer need and features. The advantages of this model are for both organizations and customers. Concerning organization, a reputation model that focuses on the right part of the business model could improve the value of organization: firms can detect the problematics and modify or eventually delete the causes of the bad reputation; a positive side effect could be the efficiency improvement related to the cost decrease and to the reward increase. Business model is a complex system where activities, competences, resources and skill are strictly linked and connected to create the value delivered by the organization to customers. A disalienation among the previous factors can develop different problematics to the organization in term of customer, internal cost, brand identity, revenue stream and cost. Customers that does not understand the value delivered by organization are not stirred to buy its products or use its service. The consequences could be the decrease of market share and brand reputation. Of course organization has not only to understand the inappropriateness of the business model but has to focus its attention on exactly the activities, resources, competence that could generate problem. This organizational behaviour is in line with the innovative role of customers where the customer is not only a user but can become partner (even cover an important role as the producer) in the business activities development. Defining the reputation using cube model can create a positive interaction between business model and customer that can work together to develop a better product and service that can produce value for both. Reputation is the major factor that formulates an opinion about a brand. The use of correct reputation in the business world is the key point to minimize risks. In today's economy, $70 \%$ to $85 \%$ of market value comes from hard-to-assess intangible assets, which makes organizations especially susceptible to anything that damages their reputation. Thank to the proposed methodology the deployment of a reputation system that takes into account the objective data of the company, together with any source of external quality assurance, minimizes the risks connected with a reputation totally built by subjective feedbacks from users.

\section{Current and future work.}

Implementation. We are currently extending VDML and ServiceML meta-models to include the presented concepts. We also plan to implement the extended meta-model on Eclipse Modeling Framework (EMF)[12] in order to develop a visual editor to develop and test the proposed modeling language.

Further extensions. In this paper we did not address topics related of measurements associated to claims nor algorithms/computation functions for feedbacks aggregation. These issues involves more technical roles in the system development like programmers. We plan to extend our model in this direction by exploiting the integration of VDML with the Structured Metrics Metamodel [13] standard.

Users evaluation. In order to test the adequacy of the proposal we have recently started to gather feedback from two kind of end-users: requirements designers and domain experts. We used the proposed modeling language to develop a website collecting feedbacks and certified informations about kids nurseries. In this context value propositions, roles, activities and capabilities that should compose the reputation of the service are very complex and peculiar, thus hard to understand by outsider of the specific domain. The use of our VDML and ServiceML extension allowed mutual understanding between requirements engineers and stakeholders avoiding the sociotechnical mismatch in communication.

\section{ACKNOWLEDGMENT}

Work partially funded by ASCENS 257414 Project, by ICT COST Action IC1201 BETTY, MIUR PRIN Project CINA Prot. 2010LHT4KM, Torino University/Compagnia San Paolo Project SALT and local research for young researchers funded by University of Torino (Computer Science Deparment).

\section{REFERENCES}

[1] D. J. Teece, "Business Models, Business Strategy and Innovation," Long Range Planning, vol. 43, no. 2-3, pp. 172 - 194, 2010, Business Models.

[2] A. J. Berre, Y. Lew, B. Elvesaeter, and H. de Man, "Service Innovation and Service Realisation with VDML and ServiceML," 2012 IEEE 16th International Enterprise Distributed Object Computing Conference Workshops, vol. 0, pp. 104-113, 2013.

[3] R. Farmer and B. Glass, Building Web Reputation Systems, 1st ed. USA: Yahoo! Press, 2010.

[4] R. Alnemr, S. Koenig, T. Eymann, and C. Meinel, "Enabling usage control through reputation objects: A discussion on e-commerce and the internet of services environments," J. Theor. Appl. Electron. Commer. Res., vol. 5, no. 2, pp. 59-76, Aug. 2010. [Online]. Available: http://dx.doi.org/10.4067/S0718-18762010000200005

[5] Y. Yao, S. Ruohomaa, and F. Xu, "Addressing common vulnerabilities of reputation systems for electronic commerce," J. Theor. Appl. Electron. Commer. Res., vol. 7, no. 1, pp. 1-20, Apr. 2012. [Online]. Available: http://dx.doi.org/10.4067/S0718-18762012000100002

[6] R. Alnemr and C. Meinel, "Why rating is not enough: A study on online reputation systems," in Collaborative Computing: Networking, Applications and Worksharing (CollaborateCom), 2011 7th International Conference on, Oct 2011, pp. 415-421.

[7] P. Lindgren and O. H. Rasmussen, "The Business Model Cube," Journal of Multi Business Model Innova-tion and technology, 2013, 3rd edition.

[8] T. Hulme, "Startup Tools." http//weijiblog.com/startp-tools/, 2012.

[9] “Object Management Group," http://www.omg.org/. 
[10] S. Clatworthy, "Innovations in service experiences: The AT-ONE method," in Proc. of the 6th International Conference on Design and Emotion, 2008

[11] F. Moyano, C. Fernandez, and J. Lopez, "Towards engineering trustaware future internet systems," in Advanced Information Systems Engineering Workshops, ser. Lecture Notes in Business Information Processing, X. Franch and P. Soffer, Eds. Springer Berlin Heidelberg, 2013, vol. 148, pp. 490-501.

[12] D. Steinberg, F. Budinsky, M. Paternostro, and E. Merks, EMF: Eclipse Modeling Framework 2.0, 2nd ed. Addison-Wesley Professional, 2009.

[13] OMG, "Structured Metrics Metamodel (SMM), Version 1.0," OMG Document formal/2012-01-05, 2012, http://www.omg.org/spec/SMM/1.0/PDF/. 